\title{
Tuning of nonlinear optic response properties for ruthenium alkynyl complexes via computational-guided structural tailoring
}

\author{
Fazira Ilyana Abd Razak a,b, ${ }^{,}$, Roswanira Abdul Wahab ${ }^{b, c}$, Rosmawati Jamaludin b, d, \\ Aliyu Adamu b, c \\ a Centre for Sustainable Nanomaterials, Ibnu Sina Institute for Scientific and Industrial Research, Universiti Teknologi Malaysia, Skudai 81310 , \\ Johor, Malaysia \\ b Department of Chemistry, Faculty of Science, Universiti Teknologi Malaysia, 81310 UTM Johor Bahru, Johor, Malaysia \\ ${ }^{c}$ Department of Biotechnology and Medical Engineering, Faculty of Biosciences and Medical Engineering, UTM, Johor, Malaysia \\ ${ }^{d}$ Kementerian Pendidikan Malaysia, 62604, Putrajaya, Malaysia
}

* Corresponding author: fazirailyana@utm.my

\section{Article history}

Received 4 July 2019

Revised 24 December 2019

Accepted 29 January 2020

Published Online 16 August 2020

\section{Graphical abstract}

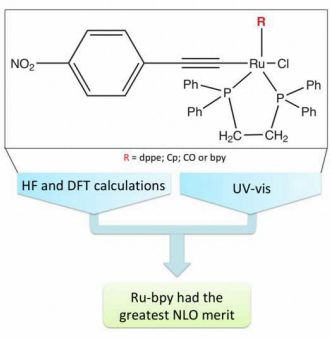

\begin{abstract}
Hartree Fock (HF) and density functional theory (DFT) methods based on a 3-21G set level were used to computationally assess the nonlinear optic (NLO) response of six ruthenium (Ru) arylalkynyl complexes. The low basis set of 3-21G was proved to provide adequate results with difference of only about $3 \%$ between calculation and experimental data. Substitution of Ru-phenyl with six simplified models of Ru-H and Ru-methyl complexes revealed that DFT-based calculations were more accurate than HF in estimating the NLO response. The calculated bond lengths and angles of Ru-methyl were in good agreement with Ru-phenyl. Given that the calculated $\mathrm{C} \equiv \mathrm{C}$ stretching vibration and UV-vis maximum absorption for Ru-methyl was comparable to Ru-phenyl, with values corresponding to $2154.56 \mathrm{~cm}^{-1}$ and $460.93 \mathrm{~nm}$, respectively. It was evident that Ru-H, Ru-methyl and Ru-phenyl complexes undergo intraligands $\pi-\pi^{*}$ and Laporte forbidden metal $d-d$ transition. Henceforth, it is affirmed that calculations using simplified $\mathrm{Ru}-\mathrm{H}$ complexes were as much as reliable as the full structure of Ru to assess the NLO response. Assessment of electron inductive effect on Ru-carbonyl (Ru-Co), Ru-cyclopentadienyl (Ru-Cp) and Ru- bipyridine (Ru-bpy) complexes revealed two absorption maxima that appeared in regions $320-375 \mathrm{~nm}$ and $382-460 \mathrm{~nm}$, which represent an intraligand $\pi-\pi^{*}$ orbital and Laporte forbidden d-d-transition, respectively. Migration of electrons from $\mathrm{Ru}$ center to the bipyridine ligand suggests a greater electron acceptor effect than Ru center to the arylalkynyl group. However, Ru conjugated to an electron withdrawing group i.e. carbonyl tend to render lower NLO response while elevating HOMO - LUMO energy gap and Ru to $\mathrm{C}_{\alpha}$ bond lengths.
\end{abstract}

Keywords: ruthenium, nonlinear optic, computational studies, Gaussian, ADF

\section{INTRODUCTION}

The quest for new organometallic materials showing nonlinear optic (NLO) properties is a facet of research that has gained significant attention of the scientific community. The vast majority of applications for which materials with NLO properties have been used in optical device technology viz. optical signal processing, switching, frequency generation, optical data storage, optical communication and image processing [1, 2]. Relevance of NLO materials for such applications stems from their inherent ability to interact with an incident light and consequently alter the properties of the light which include phase, frequency, amplitude, polarization, path and etc. An NLO material is typically a high molecular mass complex having a $\pi$ conjugated system comprising of donor and acceptor substituents linked through an intervening $\pi$-backbone which creates a push-pull system [3]. Significant achievements have been reported for pushpull systems made up of a metal center, bonded to a polarizable organic conjugated backbone i.e. chromophore, which acts as an electron donating (EDG) or withdrawing group (EWG) $[1,4]$.
So far, two classes of organometallic compounds extensively scrutinized for NLO properties are ferrocenyl and metal alkynyl complexes. Reasons for their preference are the facile functionalization and syntheses, thermal, oxidative and photochemical stability. In retrospect, Ruthenium $(\mathrm{Ru})$ arylalkynyl complexes are developed for use as second-order NLO materials, due to their versatility such as varying stereochemistry and identity of the coordinate ligands, as well as several oxidation states. The possibility of facile NLO switching by $\mathrm{Ru}$ arylalkynyl complexes is the consequence of its reversible redox properties [2]. Nonlinearity properties in $\mathrm{Ru}$ arylalkynyl complexes can be enhanced by direct ligation of metal to halogen, i.e. chloride for maximum hyperpolarizability [5]. However, the efficiency of electron donation is notably decreased with increasing size of the halogen. This shortcoming is circumvented by coordination of $\mathrm{Ru}$ to arylalkynyl instead of halogen [5]. While it has been reported in the literature that excellent yields of Ru alkynyl complexes are readily achieved [6, 7], synthesis of these complexes can be a costly and time-consuming process. For these reasons, a computational approach that enables the in silico synthesis and screening of possible Ru alkynyl complexes 
showing excellent NLO properties, prior to experimental work, appears highly useful. Aside to the possible reduction in the preparation cost, data gathered from these computational evaluations may shed light into the molecular electronic structure as well as the extent of the NLO properties in the synthesized $\mathrm{Ru}$ alkynyl complexes. For the last decade, quantum chemical techniques are the established standard tools for quantitative calculations of transition metal compounds. Thomas [8] has described that data on geometry stability, vibrational frequency, bond dissociation energy and other chemical obtained from calculations are reliable enough to complement the experimental data to assess quality of the Ru alkynyl complexes [8]. Quantum chemical calculations involving density functional theory (DFT), Hartree Fock (HF) and semi-empirical methods, each uses electron density, electronic wavefunction and wavefunction, respectively. Specifically, a semi empirical method uses experimental data simplification as basic variables in the wavefunction approach [9]. In this regard, the study uses a combination of the $a b$ initio techniques, HF and DFT to assess quality and NLO properties of Ru alkynyl complexes. HF assumes electrons move in an average central field of all electrons but neglects electron correlation from instantaneous interaction between the electrons [10]. On the other hand, DFT, which is based on Hohenberg-Kohn theorem, correlates the effects of electron and account interactions of electron pair of opposite spin in a molecular system [11]. It is a semiempirical method that uses experimental parameters to simplify all calculations and solve the approximate form of Schrodinger equation. Although HF is less accurate than DFT for quantitative prediction of energy and structure for molecular system, the latter can offer reasonable qualitative description of any type of molecular system [12]

Several studies have been aimed on varying the substituents on nitrophenylalkynyl ligand at pull fragment in $\mathrm{Ru}$ complexes as potential NLO material [13-15]. However, research on the effect of electron inductive co-ligand on NLO properties in such complexes is an area that has yet to receive much attention [16]. Herein, we report the use of simplified $\mathrm{Ru}$ alkynyl complexes and computational optimization of their electronic and molecular structures. The second part of the study used HF and DFT methods to assess the feasibility of the structure simplification approach to predict NLO properties. The objective of this study was to investigate potential of Ru alkynyl complexes as better NLO materials. Reliability in predicting NLO properties of this simplified approach was tested by comparing the computed data with those empirically determined in literature.

\section{EXPERIMENTAL}

\section{Computational methodology}

The geometry optimization, bond length, and bond angles analysis have been carried out by using HF [17] method and DFT [18] at B3LYP/3-21G level of theory [19] with no symmetrical constraint. The stability of complexes investigated by examining the molecular energy and stability data from optimization and stability calculations, respectively. Frequency calculations have also been performed using same level of theory.

All of calculations were performed usingGaussian $09 \mathrm{~W}$ software package [20]. GaussView 5.0 software was used for visualization of molecules while vibrational frequency was calculated using 0.965 scaling factor.

\section{Calculation for bond length and bond angle}

The calculation for the percentage of deviation for bond length and bond angle study follows Equation (1) below.

$$
\% \text { deviation }=\frac{\text { calculated value }- \text { experimental value }}{\text { experimental value }} \times 100
$$

\section{RESULTS AND DISCUSSION}

The study was divided into two parts, in which the first part investigated the simplification effect of phosphine ligands to determine the best method for calculation to predict NLO properties of ruthenium complexes. The second part involved replacing one of the bis(diphenylphosphino)ethane (dppe) ligand with another electron donating (EDG) or electron withdrawing groups (EWG), to cause changes in NLO properties.

\section{Simplification effect of Ru arylalkynyl complexes to computational cost}

It is a well-known fact that calculation of large organometallic complexes can be computationally expensive particularly when involving large and bulky ligands. Most of the organometallic complexes investigated in this study are comprised of bulky ligands such as dppe and bipyridine. To simplify the calculation, all phenyl groups in the $\mathrm{Ru}$ alkynyl complexes were substituted with either methyl groups or hydrogen atoms. It is worth mentioning here, phosphine ligands in organometallic complexes have the general formula $\mathrm{PR}_{3}$, where $\mathrm{R}$ can be alkyl, aryl, $\mathrm{H}$ or halogen atom. These ligands act as $\sigma$-bond donors that interact with p-orbitals lone pair electrons of phosphorous atom to form $\sigma$-bonds. The interaction of phosphine-metal through backdonation from filled d-orbital of metal to empty phosphorous atom can potentially enhance stability of the formed coordinate complexes, hence improving NLO properties of the material. Careful selection of substituents, $\mathrm{R}$ on the phosphorous atom can have a profound impact on the properties of NLO in $\mathrm{Ru}$ arylalkynyl complexes. The study expects that each $\mathrm{R}$ group would exert a change in donor strength to ruthenium, which consequently is delocalized through the complex to effectively modulate NLO property.

The molecular structures of three $\mathrm{Ru}$ arylalkynyl complexes with varying phosphine ligands $\mathrm{R}$ groups used in the study are shown in Fig. 1. Since all of three complexes are electrically neutral, optimization as well as inspection of their molecular energies, bond lengths and angles were performed using DFT and HF methods under zero charge and singlet spin multiplicity. The time taken to complete the optimization calculation for the complexes is summarized in Table 1. It was revealed that DFT required a longer time than the HF method to converge. This is attributable to the fact that DFT method involves an explicit term that fully describes the way by which the motion of an electron is affected by the motion of all other electrons in the system (i.e. electron relativistic effects), an aspect ignored in the HF method [21]. Ru-H being the simplest of the three complexes, as anticipated recorded the shortest time for the optimization calculation to converge for both DFT and HF methods. Whereas, convergence occurred last for Ru-phenyl consistent with its structure being the most complex among the assessed $\mathrm{Ru}$ arylalkynyl complexes. The data hence, supports the fact that computational time intensiveness increases with increasing complexity of the ligand complex.
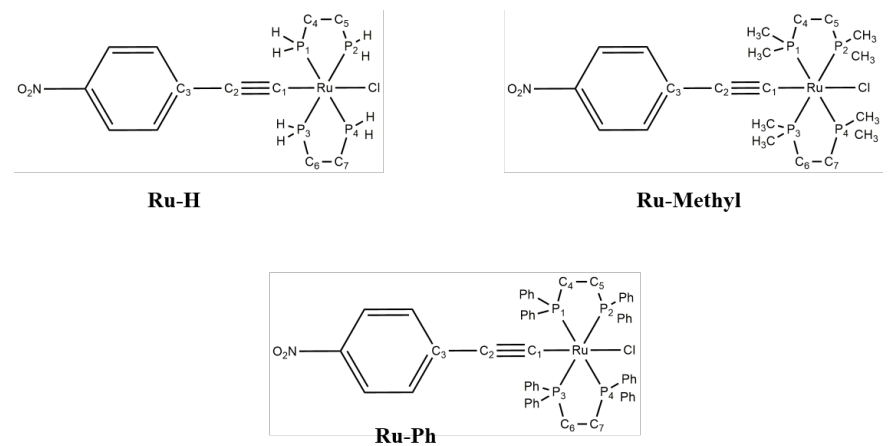

Fig. 1 Ruthenium arylalkynyl complexes with various substitutions on phosphine ligand for energy calculation. 
Table 1 Computational time for Ru complex optimization.

\begin{tabular}{lll}
\hline & \multicolumn{2}{c}{ Time (h) } \\
\cline { 2 - 3 } Complex & HF & DFT \\
\hline Ru-H & 1.08 & 1.80 \\
Ru-methyl & 13.78 & 27.65 \\
Ru-phenyl & 27.98 & 145.67 \\
\hline
\end{tabular}

Molecular energies were calculated in atomic unit (a.u) (Fig. 2) and comparison of molecular energies in the three $\mathrm{Ru}$ arylalkynyl complexes revealed that Ru-phenyl scored the lowest energy ( -8726.73 a.u and -8748.81 a.u), followed by Ru-methyl $(-7211.17$ a.u and -7223.40 a.u), and the highest is Ru-H (-6900.48 a.u and -6910.46 a.u), for both HF and DFT calculations, respectively. For all the studied complexes, as expected, the DFT method generally computed lower molecular energies as compared to $\mathrm{HF}$, with variations between 10-22 a.u, agreeing well with energy variances reported for similar calculation methods, as described by [22]. The observable general difference in calculated molecular energies of the three $\mathrm{Ru}$ arylalkynyl complexes became characteristically larger as size of the Ru complex increases. The trend seen here mirrors the fact that HF calculations did not account for the relativistic effects of higher number of electrons within larger Ru arylalkynyl complexes. Our result corroborates previous calculations by [21].

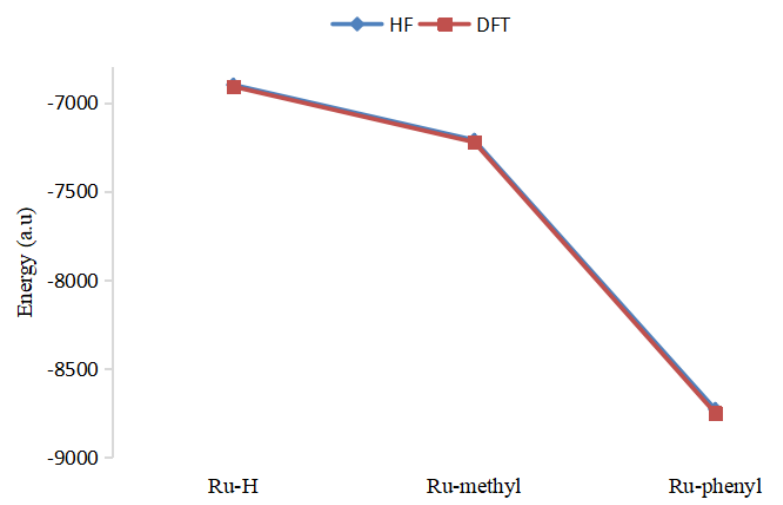

Fig. 2 Energy calculation of ruthenium arylalkynyl complexes using HF and DFT.

According to the literature, the octahedral molecular geometry of ruthenium complexes constructed by two ligands, each a chloride and p-nitroarylacetylide, would typically adopt a trans position with respect to each other and all four atoms would occupy the equatorial plane of the octahedron [23]. Optimized structures of all ruthenium complexes computed in this study would also assume a relatively similar array, as described above. For this study, calculated bond lengths and angles of the three ruthenium complexes were compared to those of Ru-phenyl reported by Younus et al. [23]. Our survey shows that bond length and angle of Ru-phenyl calculated by Younus et al. [23] were in close agreement with those calculated for $\mathrm{Ru}-\mathrm{H}$ by [24], except the latter employed the Amsterdam Density Functional (ADF) method in their calculations. Similar ranges of bond lengths and angles of the computed Ru-phenyl were also observed in previously reported $\mathrm{Ru}$ arylalkynyl complexes [23, 25] (Table 2 and Table 3). By using Equation 1 (refer section 2.2) in comparing with the empirical studies, it was shown that the computed results gave deviations in bond lengths and angles by as much as $0.5-11 \%$. Remarkably, DFT produced smaller deviations, at $\sim 5.2 \%$ as compared to $\sim 11.11 \%$ in the HF method, indicating that DFT offers a higher accuracy in calculation of such molecular properties.
Table 2 Selected bond lengths for Ru complexes.

\begin{tabular}{|c|c|c|c|c|c|c|c|}
\hline \multirow{3}{*}{$\begin{array}{l}\text { Atomic } \\
\text { bond }\end{array}$} & \multicolumn{7}{|c|}{ Bond length $(\AA)$} \\
\hline & \multicolumn{2}{|c|}{ Ru-H } & \multicolumn{2}{|c|}{ Ru-methyl } & \multicolumn{2}{|c|}{ Ru-phenyl } & \multirow[t]{2}{*}{$\mathbf{E X P}^{\mathbf{a}}$} \\
\hline & HF & DFT & HF & DFT & HF & DFT & \\
\hline $\mathrm{Ru}-\mathrm{Cl}$ & 2.58 & 2.56 & 2.61 & 2.59 & 2.63 & 2.63 & 2.50 \\
\hline Ru- $C_{1}$ & 2.09 & 2.00 & 2.10 & 1.99 & 2.09 & 1.98 & 1.99 \\
\hline $\mathrm{C}_{1}-\mathrm{C}_{2}$ & 1.21 & 1.23 & 1.21 & 1.24 & 1.21 & 1.23 & 1.21 \\
\hline $\mathrm{C}_{2}-\mathrm{C}_{3}$ & 1.42 & 1.49 & 1.42 & 1.41 & 1.42 & 1.41 & 1.44 \\
\hline Ru-P 1 & 2.52 & 2.39 & 2.51 & 2.41 & 2.59 & 2.46 & 2.35 \\
\hline $\mathrm{Ru}-\mathrm{P}_{2}$ & 2.52 & 2.39 & 2.51 & 2.40 & 2.61 & 2.45 & 2.36 \\
\hline Ru- $P_{3}$ & 2.52 & 2.39 & 2.51 & 2.40 & 2.61 & 2.44 & 2.39 \\
\hline $\mathrm{Ru}-\mathrm{P}_{4}$ & 2.52 & 2.39 & 2.51 & 2.40 & 2.61 & 2.45 & 2.37 \\
\hline
\end{tabular}

a. Younus et al. (1999)

Table 3 Selected bond angle for Ru complexes.

\begin{tabular}{|c|c|c|c|c|c|c|c|}
\hline \multirow{3}{*}{$\begin{array}{l}\text { Atomic } \\
\text { angle }\end{array}$} & \multicolumn{7}{|c|}{ Bond angle $\left({ }^{\circ}\right)$} \\
\hline & \multicolumn{2}{|c|}{ Ru-H } & \multicolumn{2}{|c|}{ Ru-methyl } & \multicolumn{2}{|c|}{ Ru-phenyl } & \multirow[t]{2}{*}{ EXP $^{a}$} \\
\hline & HF & DFT & HF & DFT & HF & DFT & \\
\hline $\begin{array}{l}\text { Cl-Ru- } \\
\mathrm{C}_{1}\end{array}$ & 178.84 & 178.5 & 178.7 & 178.5 & 178.0 & 175.0 & 176.2 \\
\hline $\begin{array}{l}\text { Ru-C }{ }_{1-} \\
\mathrm{C}_{2}\end{array}$ & 179.94 & 179.6 & 179.5 & 179.2 & 177.6 & 178.4 & 175.3 \\
\hline $\begin{array}{l}\mathrm{C}_{1-}-\mathrm{C}_{2-}- \\
\mathrm{C}_{3}\end{array}$ & 179.94 & 179.9 & 179.4 & 179.5 & 178.4 & 179.4 & 174.4 \\
\hline $\begin{array}{l}\mathrm{P}_{1}-\mathrm{Ru}- \\
\mathrm{P}_{2}\end{array}$ & 81.72 & 83.61 & 82.76 & 84.38 & 81.96 & 82.93 & 83.23 \\
\hline $\begin{array}{l}\mathrm{P}_{2}-\mathrm{Ru}- \\
\mathrm{P}_{3}\end{array}$ & 98.19 & 96.40 & 96.83 & 95.34 & 98.69 & 96.92 & 95.52 \\
\hline $\begin{array}{l}\mathrm{P}_{3}-\mathrm{Ru}- \\
\mathrm{P}_{4}\end{array}$ & 81.73 & 83.61 & 82.76 & 84.38 & 80.04 & 82.71 & 82.58 \\
\hline $\begin{array}{l}\mathrm{P}_{4}-\mathrm{Ru}- \\
\mathrm{P}_{1}\end{array}$ & 98.08 & 96.10 & 97.60 & 95.87 & 99.32 & 97.30 & 98.66 \\
\hline
\end{tabular}

${ }^{a}$ Younus et al. (1999)

Fig. 3 clearly shows that the calculated values of DFT were closer to experimental values for all three $\mathrm{Ru}$ arylalkynyl complexes, with comparable results for $\mathrm{C} 2-\mathrm{C} 3$ and $\mathrm{C} 1-\mathrm{C} 2$ bond lengths, corresponding to $1.41-1.49 \AA$ and $1.21-1.24 \AA$, respectively. The values corresponded well with experimental values observed by Younus, et al. [23] and Kharbani et al. [25]. The good agreement between DFT calculated values with those obtained empirically is related to the method employing spatial dependent electron density approach. This approach is capable of accounting for small inter-electronic distance to calculate the energy, even with the use of small basis set such as 3$21 \mathrm{G}$. By this approach, every single electron function as one particle system as opposed to HF method, which approximates total electron functions as one particle system [26]. 


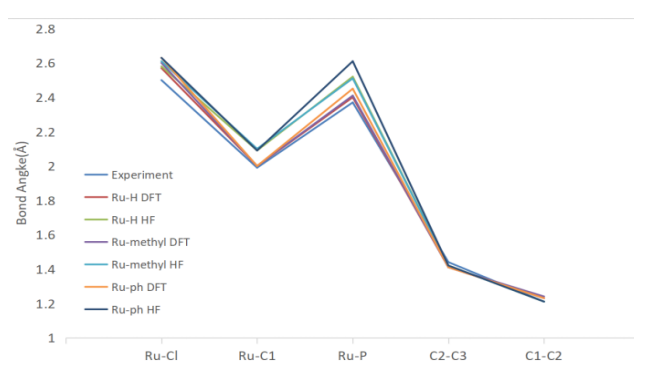

Fig. 3 Comparison of calculated value and experimental values of bond lengths of ruthenium arylalkynyl complexes

Bond angles computed in this study were characteristic of the repulsive forces between electrons during their adoption of a stable geometry. While all the assessed ruthenium complexes belonged to the $\mathrm{C} 1$ point group, the bond angles computed in this study were quite varied despite employing the same. Despite the differences, data computed by HF and DFT methods corroborated previous experimental results. The computed bond angles corresponded excellently with linear geometry arrangements of $\mathrm{Cl}-\mathrm{Ru}-\mathrm{Cl}, \mathrm{Ru}-\mathrm{Cl}-$ $\mathrm{C} 2$ and $\mathrm{C} 1-\mathrm{C} 2-\mathrm{C} 3$ as reported by Abdul Razak [3]. Consequently, it was discovered that internal bond angle of $\mathrm{P}-\mathrm{Ru}-\mathrm{P}\left(81-84^{\circ}\right)$ is smaller than the external bond angle $\left(95-99^{\circ}\right)$ strongly agreement with previous study which is presumably because of stronger intramolecular covalent bonds as compared to intermolecular van der Waals forces in the phosphine ligands [15]. Notwithstanding the different phosphine-ligand systems, the DFT method computed comparable bond lengths and angles in the three ruthenium complexes, in conjunction with the unsymmetrical geometry between the diphospine ethane ligand ligated to ruthenium, all of which strongly affirmed an earlier experiment reported by Younus et al. [23]. Our data was also comparable with those generated from Amsterdam Density Functional (ADF) software. It was shown that Ru-phenyl bond lengths calculated by Gaussian software's (HF and DFT methods) and ADF software being relatively similar and exhibited narrow deviations between $0.50-3.38 \%$, as when compared to the experimental values (Table 4). These findings attest to the comparability of the Gaussian software to that of ADF for computing bond lengths of ruthenium complexes using the applied basis set. This also means that structure simplification of ruthenium complexes for ab initio DFT and HF calculations can be accurately applied to assessed their corresponding NLO properties and to aid in the development of NLO materials.

Table 4 Selected bond lengths of $\mathrm{Ru}$ complexes generated using Gaussian and ADF software.

\begin{tabular}{cccc}
\hline $\begin{array}{l}\text { Atomic } \\
\text { bond }\end{array}$ & $\begin{array}{l}\text { Experimental } \\
\text { value }^{\mathrm{a}},(\AA)\end{array}$ & $\begin{array}{l}\text { GaussianW09 } \\
(\mathrm{DFT} 3-21 \mathrm{G}), \AA\end{array}$ & $\begin{array}{l}\text { ADF } \\
(\mathrm{TD}-\mathrm{DFT})^{\mathrm{b}}, \AA\end{array}$ \\
\hline $\mathrm{Ru}-\mathrm{C}_{1}$ & 1.99 & 1.98 & 2.004 \\
$\mathrm{Ru}-\mathrm{P}$ & 2.37 & 2.45 & 2.286 \\
\hline
\end{tabular}

${ }^{\mathrm{b}}$ Abdul Razak (2015)

\section{Calculated UV-Vis absorption spectra}

Fig. 4 shows the UV-Vis spectra of the investigated complexes in gas phase. Ru-H, Ru-methyl, and Ru-phenyl recorded their first absorption maxima $\left(\lambda_{\max }\right)$ at $432.28 \mathrm{~nm}, 462.79 \mathrm{~nm}$ and $460.93 \mathrm{~nm}$, respectively, whereas their corresponding second absorption bands occurred at $320.79 \mathrm{~nm}, 332.08 \mathrm{~nm}$ and $342.91 \mathrm{~nm}$. Bands appearing in the spectral region between $250-375 \mathrm{~nm}$ refer to the intraligand $\pi-\pi^{*}$ transitions while Laporte forbidden metal $\mathrm{d}-\mathrm{d}$ transition band appears between 400-450 nm [5, 27]. Notably, Ru-methyl and Ru-phenyl exhibited higher $\lambda_{\max }$ absorption region than $\mathrm{Ru}-\mathrm{H}$ which represent considerably greater electron delocalization activities in the two complexes following their smaller energy gaps between the bonding and antibonding orbitals. The experimental value for absorption $\mathrm{Ru}-$ phenyl in the solvent, THF corresponds to $477 \mathrm{~nm}$ [28], which is a difference by $17 \mathrm{~nm}$ with that calculated value for Ru-phenyl. This variation can be rationalized to the solvent effect that was not considered in the ab initio DFT and HF calculations. However, previous theoretical studies have specified that the omission of the solvent effect only minimally impacts the calculated spectra, in relevance to both intensity of the major single-photon transitions as well as the band position $[29,30]$.

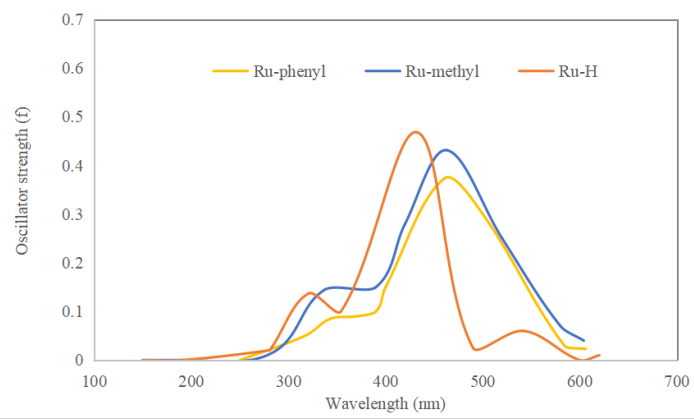

Fig. 4 UV-vis plot of absorption band of ruthenium arylalkynyl complexes.

\section{Effect of ruthenium phosphine ligand substitution with dppe derivatives on NLO properties}

The introduction of ruthenium center to different conjugated system and electron inductive effect is expected to cause changes in the electronic structure and electron excitation spectra. Complexes in Fig. 5 were chosen as target compounds for this study as they provide divergence in pull-push system govern by the chosen ligands. The energies of the complexes were minimized by optimization to obtain the stable structures of the complexes. Fig. 6 shows the energy of ruthenium complexes as calculated by the HF and DFT methods. HF method calculated energies were consistently higher than the DFT, with variances ranging between 14-22 a.u. The data support earlier trend in calculated energies for $\mathrm{Ru}-\mathrm{Cp}, \mathrm{Ru}-\mathrm{CO}$ and $\mathrm{Ru}$-bpy as represented by $\mathrm{Ru}-\mathrm{H}$, Ru-methyl and Ru-phenyl (Fig. 2). The lowest energy minimum calculated for Ru-phenyl infers its greater stability over other ruthenium complexes and its potential to be successfully design and synthesize in the laboratory. Ru-CO recorded a relatively similar energy of $\sim-7500$ a.u as for Ru-bpy, while Ru-Cp exhibited the highest energy minimum at $\sim-7200$ a.u.

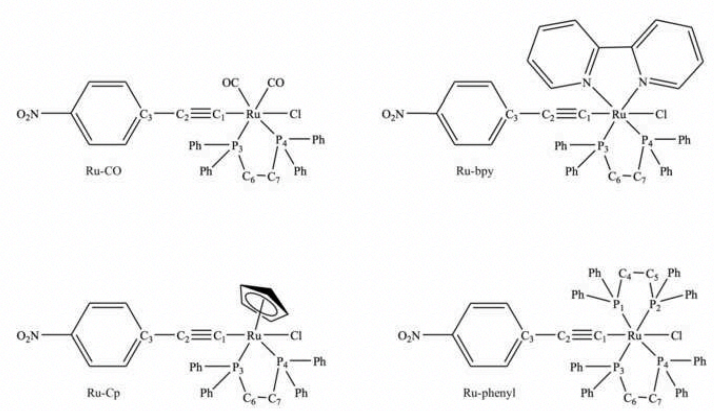

Fig. 5 Ruthenium arylalkynyl complexes with various substitutions on phosphine ligand for NLO studies

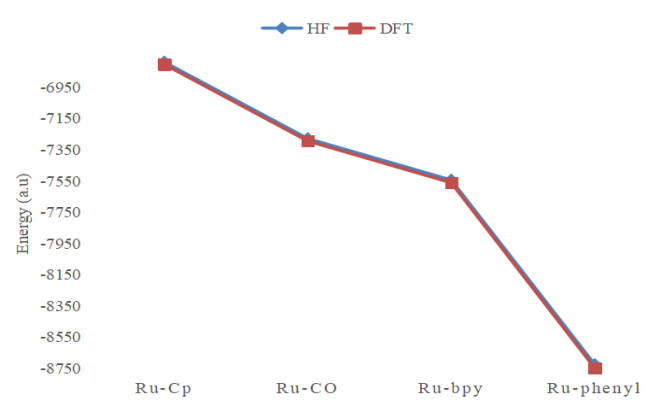

Fig. 6 Energy of ruthenium dppe derivatives calculated by HF and DFT method. 
It is clearly shown that the $\mathrm{C} \equiv \mathrm{C}$ stretching frequency for most complexes fell in the spectral region of $2179-2230 \mathrm{~cm}^{-1}$, with the highest vibration observed for Ru-CO complex. However, the experimental value for Ru-Cp (Table 5) was $2056 \mathrm{~cm}^{-1}$ lower than the computed. Taking these values into consideration, this means that the complex having an electron withdrawing ligand at push fragment $\mathrm{(Ru}-$ $\mathrm{CO})$ exerted its vibration at the highest frequency. This is contradictory to when ligand is presented at pull fragment of NLO material, as previously described by Younus et al. [23].

Table $5 \mathrm{C} \equiv \mathrm{C}$ IR frequency of ruthenium arylalkynyl complexes.

\begin{tabular}{ccc}
\hline Complex & Experimental $\left(\mathrm{cm}^{-1}\right)$ & Calculated $\left(\mathrm{cm}^{-1}\right)$ \\
\hline Ru-CO & NA & 2230 \\
Ru-bpy & NA & 2166 \\
Ru-Cp & 2056 & 2179 \\
\hline
\end{tabular}

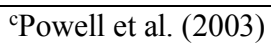

UV-Vis spectra of Ru-dppe derivatives calculated from DFT method is illustrated in Fig. 7. Ru-CO showed weak absorption band at $321 \mathrm{~nm}$ and a strong absorption at $383 \mathrm{~nm}$ while characteristic signals for Ru-bpy appeared as a weak band at $376 \mathrm{~nm}$ and a strong band at $437 \mathrm{~nm}$. Ru-Cp was calculated to absorb weakly at $374 \mathrm{~nm}$ and strongly at $432 \mathrm{~nm}$. It is important to note that the wavelength of the strong absorption band of Ru-Cp calculated here is consistent with the experimentally determined value of $447 \mathrm{~nm}$ [31]. This indicates the $a b$ initio methods employed in the study were accurate and suitable to validate the corresponding experimental results. Charge transfer bands at $320.59 \mathrm{~nm}, 375.8 \mathrm{~nm}$ and $374.48 \mathrm{~nm}$, represent the wavelengths at which the weak bands of the Ru-dppe derivatives complexes were absorbed through the $\pi-\pi^{*}$ intraligand transition, while strong bands in the region near $400-450 \mathrm{~nm}$ were consistent with Laporte forbidden metal $\mathrm{d}-\mathrm{d}$ transition, as described by Manjunatha et al. [27] and De et al. [5].

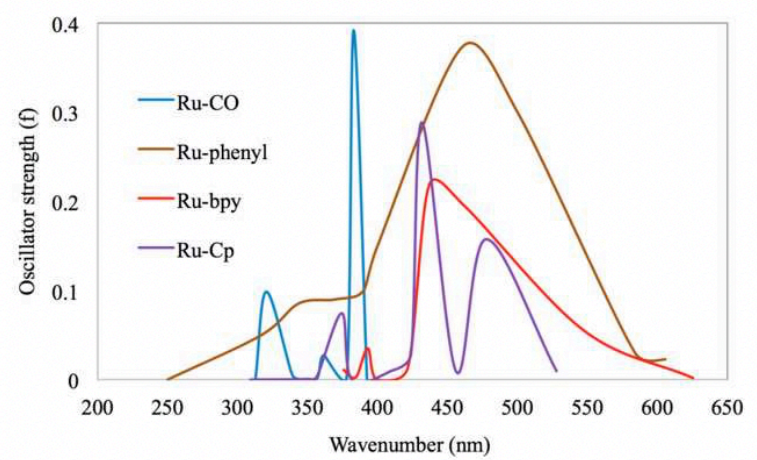

Fig. 7 UV-vis absorption band of ruthenium dppe derivatives.

On contrary, ruthenium complexes having electron resonance ligands showed higher absorption bands than those ligands bound to EWG, which occurred alongside a bathochromic shift from at $382 \mathrm{~nm}$ to $461 \mathrm{~nm}$. Increasing size of the conjugated system concomitantly occur with the absorption maxima shifting to higher wavelength. The frequency and excitation energy are decreased, obeying Equation 2. $\lambda_{\max }$ in all ruthenium complexes were seen to increase with increasing number of aromatic rings at push fragment ( $\lambda$ max: $\mathrm{Ru}-\mathrm{CO}<\mathrm{Ru}-\mathrm{Cp}<$ Ru-bpy to Ru-phenyl), along with a decreasing absorption frequency.

$$
\Delta \mathrm{E}=h c / \lambda
$$

where,

$\Delta \mathrm{E}=$ excitation energy,

$\mathrm{h}=$ Planck constant, $6.626 \times 10^{-34} \mathrm{Js}$,

$\mathrm{c}=$ speed of light, $3.0 \times 10^{8} \mathrm{~m} / \mathrm{s}$,

$\lambda=$ wavelength of excited electron.

It is because that electron conjugation results in intramolecular charge transfer from donor to acceptor group. The highest occupied molecular orbitals (HOMO) - lowest unoccupied molecular orbitals (LUMO) energy gap implies the strength of charge transfer interaction of the $\pi$ conjugated bridge between the electron donor side at push fragment to electron acceptor moiety at pull fragment [32] in the NLO material. The computed energy for LUMO and HOMO (in hatree unit) of titled complexes are -0.07798 and $-0.1794 ;-0.0873$ and $-0.2160 ;-0.0688$ and -0.1758 ; and -0.0762 and -0.1819 for Ru-bpy, $\mathrm{Ru}-\mathrm{CO}, \mathrm{Ru}-\mathrm{Cp}$ and Ru-phenyl, respectively. Equation 3 was used to calculate the HOMO-LUMO energy gaps and the results are illustrated in Fig. 8. The calculations indicate that all assessed ruthenium complexes have small energy gap hence, implying that their stability, polarizability with high tendency to transfer charge; which are characteristics of good NLO materials [33]. Notably, a decreasing HOMO-LUMO energy gap from $\mathrm{Ru}-\mathrm{CO}, \mathrm{Ru}-\mathrm{Cp}, \mathrm{Ru}-$ phenyl to Ru-bpy was observed. It is described that the most significant degree of intramolecular charge transfers from the endcapping electron donor to the efficient electron acceptor occur via a $\pi$ conjugated path [34], which is evident in the HOMO-LUMO energy gap of the three Ru alkylaryl complexes.

$$
\mathrm{E}_{\text {gap }}=\mathrm{E}_{\text {LUMO }}-\mathrm{E}_{\text {HOMO }}
$$

Frontier molecular analysis revealed that the charge transfer of the titled complexes occurred from push ruthenium fragment to pull arylalkynl fragment. This is supported by a higher electron density at the donor part in HOMO as well as at the acceptor part in LUMO. For the exception of Ru-bpy (Fig. 8), it was clear that electron density is higher at linear fragment of Cl-Ru-arylalkynyl in HOMO distribution, while the electrons accumulate on bipyridine moiety at the LUMO part. This is further corroborated by results of atomic charge analysis which show that both nitrogen atoms at the bipyridine ligand bear a charge between -0.668 to -0.692 , which is more electronegative than $\mathrm{C} 1$ (atomic charge $=-0.206$ ). Hence, the denser electrons on Ru-bpy complexes are transferred from the linear fragment of $\mathrm{Cl}-\mathrm{Ru}-$ arylalkynyl to the bipyridine moiety. This indicates that bipyridine group is a stronger electron acceptor than the nitrobenzene acetylene fragment.

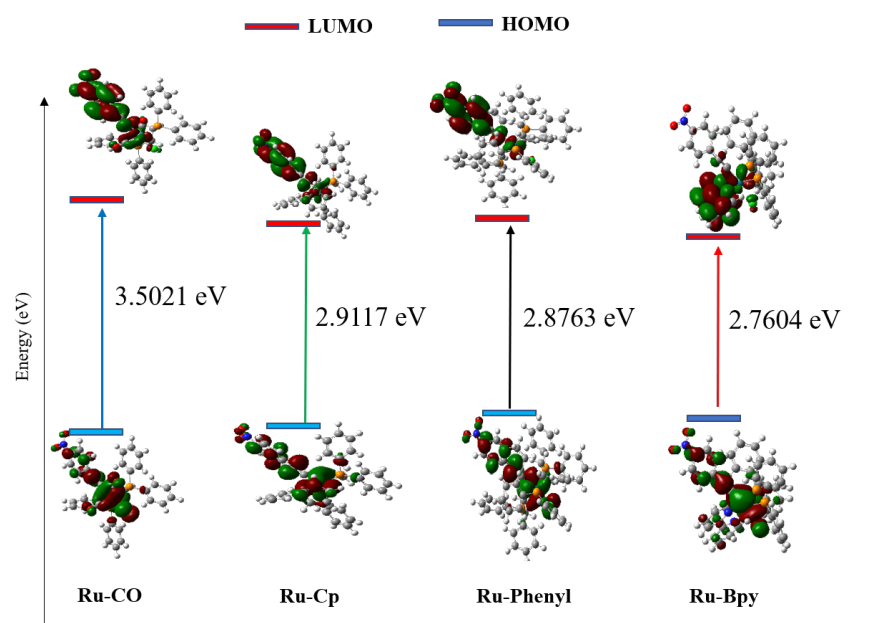

Fig. 8 Schematic energy level diagram of frontier molecular orbital of ruthenium dppe derivatives. 
Data on ruthenium-carbon bond lengths and corresponding spectroscopic characterization of the complexes (Fig. 7) were used to guide our initial guess of the strength of NLO response. Based on earlier calculated and empirically established ruthenium to carbon distance, the strength of $\pi$-backbonding began from the electron rich metal to alkynyl organic fragment $[13,15,35-37]$. The greater $\pi$ backbonding that occurred from the electron rich metal to alkynyl organic fragment implies a higher NLO merit, while variations in other bond distances are thought to be less meaningful [31]. These results therefore corroborate reliability of the calculated HOMOLUMO energy gaps to assist ab initio prediction in influencing efficiency of intramolecular charge transfer in NLO materials.

The shorter ruthenium to carbon bond length in Ru-bpy evidently indicates that the complex has a higher strength of $\pi$-backbonding from the electron rich ruthenium to alkynyl organic fragment. Likewise, the corresponding lowest HOMO- LUMO energy gap implies that the complex has stronger charge transfer capability. This means that the Ru-bpy probably possessed greater NLO merit. Interestingly, Ru- bpy has been known to display anomalous push and pull system in comparison to other ruthenium arylalkynyl derivatives, in which bipyridine acts as the pull fragment. Throughout, $\mathrm{Ru}-\mathrm{CO}$ complex was observed to show consistency in terms of bond length and spectroscopic data. However, the complex possessed the least NLO properties as reflected in the longest ruthenium to carbon bond, lowest UV-vis absorption band alongside the largest HOMO-LUMO energy gap. This assumption is supported by Powell et al. [31] in their study, which revealed that upon substitution of the dppe ligand by a carbonyl group, quadratic coefficient $(\beta)$ drops from $161 \times 10^{-30}$ to 27 x $10^{-30}$ esu. Such trend was clearly observed in our study. The $\beta_{\text {tot }}$ was calculated by using the following equation [7].

$$
\begin{aligned}
\beta_{\mathrm{tot}}= & \left(\beta_{\mathrm{x}}{ }^{2}+\beta_{\mathrm{y}}{ }^{2}+\beta_{\mathrm{z}}{ }^{2}\right)^{0.5} \\
\beta_{\mathrm{tot}}= & {\left[\left(\beta_{\mathrm{xxx}}+\beta_{\mathrm{xyy}}+\beta_{\mathrm{xzz}}\right)^{2}+\left(\beta_{\mathrm{yyy}}+\beta_{\mathrm{yxx}}+\beta_{\mathrm{yzz}}\right)^{2}+\left(\beta_{\mathrm{xxx}}+\beta_{\mathrm{xyy}}+\right.\right.} \\
\left.\left.\beta_{\mathrm{xzz}}\right)^{2}+\left(\beta_{\mathrm{zxx}}+\beta_{\mathrm{zyy}}+\beta_{\mathrm{zzz}}\right)^{2}\right]^{0.5} & \cdots
\end{aligned}
$$

In one hand, Ru-phenyl is computationally expected to exert better NLO response over the other two complexes. This is in reference to the shorter ruthenium to carbon bond length and lower HOMO-LUMO energy gap than Ru-Cp. However, this contradicted earlier empirical experiments that showed $\mathrm{Ru}-\mathrm{Cp}$ having greater NLO response than Ru-phenyl. This was based on the substantially higher quadratic coefficient of $\mathrm{Ru}-\mathrm{Cp}$, that corresponded to $161 \times 10^{-30}$ esu [31] as compared to $55 \times 10^{-30}$ esu in Ru-phenyl [28]. The discrepancy was probably attributed to a more efficient donor property in $\mathrm{Cp}$ than in the dppe ligand. Essentially, the key determinant of NLO response lies in size of the employed $\pi$ system [38].

\section{CONCLUSION}

The study assessed the presence of electron inductive group that can influence bond lengths but not bond angles in $\mathrm{Ru}$ complexes using ab initio methods of DFT and HF. The present study demonstrates that optimization of bulky $\mathrm{Ru}$ complex can be computationally simplified to reduce the computational cost and time, by employing simpler ligands that have similar electron inductive effects, in replacement of the more complex ones. Based on the computed data of DFT and HF, Ru-bpy is presumed to possess the greatest NLO merit based on its shortest Ru-C1 bond length and low HOMO-LUMO energy gap in comparison to two other ruthenium complexes, Ru-CO and Ru-Cp. Consistently, the close agreement between ruthenium complexes from experimental results with the calculated simplified ruthenium complexes using DFT method, indicates the accuracy and practicality of the proposed approach in expediting identification of materials with good NLO properties. Moreover, the approach adopted here may prove useful in assessing
NLO properties of $\mathrm{Ru}$ complexes having longer $\pi$-conjugation systems and the use of different metal centers, with regards to increasing their efficiency of charge transfer.

\section{ACKNOWLEDGEMENT}

We greatly acknowledge funding from Universiti Teknologi Malaysia under grant of Tier 1 (Vot Q.J130000.2526.20H08), and Fundamental Research Grant Scheme (FRGS, Vot R.J130000.7826.4F957) for the support of this work. We also would like to acknowledge valuable help and suggestions provided by our colleagues.

\section{REFERENCES}

[1] M. H. Garcia, P. J. Mendes, M. P. Robalo, A. R. Dias, J. Campo, W Wenseleers, E. Goovaerts. Compromise between conjugation length and charge-transfer in nonlinear optical $\eta 5$-monocyclopentadienyliron (II) complexes with substituted oligo-thiophene nitrile ligands: Synthesis, electrochemical studies and first hyperpolarizabilities. Journal Of Organometallic Chemistry 692(14) (2007) 3027- 3041.

[2] G. Grelaud, M. P. Cifuentes, F. Paul, M. G. Humphrey. Group 8 metal alkynyl complexes for nonlinear optics. Journal of Organometallic Chemistry 751 (2014) 181-200.

[3] F. I. Abdul Razak. Iron, Ruthenium and Osmium alkynyl Complexes: Synthesis, Linear Optical and Computational Studies. PhD Dissertation, Australia National University. (2015).

[4] P. D. Zoon, I. H. Van Stokkum, M. Parent, O. Mongin, M. BlanchardDesce, A. M. Brouwer. Fast photo-processes in triazole-based push-pull systems. Physical Chemistry Chemical Physics 12(11) (2010) 2706-2715.

[5] S. De, R. Mitra, A. Samuelson, P. K. Das. First hyperpolarizability of Ruhalf- sandwich complexes: The effect of halogen atom substitution on the ancillary ligand. Journal of Organometallic Chemistry 785 (2015) 72-76.

[6] K. A. Green, M. P. Cifuentes, M. Samoc, M. G. Humphrey. Metal alkynyl complexes as switchable NLO systems. Coordination Chemistry Reviews 255(21-22) (2011) 2530-2541.

[7] A. Merhi, G. Grelaud, K. A. Green, N. H. Minh, M. Reynolds, I. Ledoux, A. Barlow, G. Wang, M. P. Cifuentes, M. G. Humphrey. A hybrid ruthenium alkynyl/zinc porphyrin "Cross Fourchée" with large cubic NLO properties. Dalton Transactions 44(17) (2015) 7748-7751.

[8] R. Thomas. Computational Organometallic Chemistry, Marcel Dekker Inc., New York, 2001.

[9] E. I. Solomon, A. B. P. Lever. Inorganic Electronic Structure and Spectroscopy, Applications and Case Studies, Wiley-Interscience, 1999.

[10] A. Vlček Jr, S. Záliš. Modeling of charge-transfer transitions and excited states in d6 transition metal complexes by DFT techniques. Coordination Chemistry Reviews 251(3-4) (2007) 258-287.

[11] P. Hohenberg, W. Kohn. Inhomogeneous electron gas. Physical Review 136(3B) (1964) B864.

[12] B. O. Roos, R. Lindh, P. Å. Malmqvist, V. Veryazov, P. O. Widmark, Hartree - Fock Theory, Multiconfigurational Quantum Chemistry (2016) 43-58.

[13] J. E. Mc Grady, T. Lovell, R. Stranger, M. G. Humphrey, Bonding of $\eta 1$ acetylide ligands to electron-rich ruthenium centers: Can electronwithdrawing ligands induce significant metal-to-ligand back-bonding?, Organometallics 16(18) (1997) 4004-4011.

[14] M. Rohr, M. Günther, F. Jutz, J.-D. Grunwaldt, H. Emerich, W. van Beek, A. Baiker. Evaluation of strategies for the immobilization of bidentate ruthenium-phosphine complexes used for the reductive amination of carbon dioxide. Applied Catalysis A: General 296(2) (2005) 238-250.

[15] F. Paul, B. G. Ellis, M. I. Bruce, L. Toupet, T. Roisnel, K. Costuas, J.-F. Halet, C. Lapinte. Bonding and substituent effects in electron-rich mononuclear ruthenium $\sigma$-Arylacetylides of the formula $\left[(\eta 2-d p p e)\left(\eta^{5}\right.\right.$ $\left.\left.\mathrm{C}_{5} \mathrm{Me}_{5}\right) \mathrm{Ru}(\mathrm{C}: \mathrm{C})-1,4-\left(\mathrm{C}_{6} \mathrm{H}_{4}\right) \mathrm{X}\right]\left[\mathrm{PF}_{6}\right] \mathrm{n}\left(\mathrm{n}=0,1 ; \mathrm{X}=\mathrm{NO}_{2}, \mathrm{CN}, \mathrm{F}, \mathrm{H}\right.$, $\mathrm{OMe}, \mathrm{NH} 2$ ). Organometallics 25(3) (2006) 649-665.

[16] M. Al-Noaimi, M. Sunjuk, M. El-khateeb, S. F. Haddad, A. Haniyeh, M. AlDamen. Cis-trans Isomerism in mixed-ligand ruthenium (II) complexes containing bis (phosphine) and azoimine ligands. Polyhedron 42(1) (2012) 66-73.

[17] J. Valatin. Generalized hartree-fock method. Physical Review 122(4) (1961) 1012.

[18] R. G. Parr, S. R. Gadre, L. J. Bartolotti. Local density functional theory of atoms and molecules. Proceedings of the National Academy of Sciences 76(6) (1979) 2522-2526.

[19] T. Clark, J. Chandrasekhar, G. W. Spitznagel, P. V. R. Schleyer. Efficient diffuse function-augmented basis sets for anion calculations. III. The $3-21+\mathrm{G}$ basis set for first-row elements, Li-F. Journal of Computational Chemistry 4(3) (1983) 294-301. 
[20] M. J. Frisch, G. W. Trucks, H. B. Schlegel, G. E. Scuseria, M. A. Robb, J. R. Cheeseman, G. Scalmani, et al. Gaussian 09, Revision A.1, Gaussian Inc. Wallingford CT (2009).

[21] T. Schlick. Theoretical and computational approaches to biomolecular structure. In molecular modeling and simulation: An interdisciplinary guide: An interdisciplinary guide (Vol. 21). (pp. 237-265) Springer Science \& Business Media., (2010).

[22]P. F. Pohan. Computational Calculation of Ruthenium and Alkynyl Complexes by Using Gaussian09. Degree Dissertation. Universiti Teknology Malaysia.Skudai. (2017).

[23] M. Younus, N. J. Long, P. R. Raithby, J. Lewis, N. A. Page, A. J. White, D. J. Williams, M. C. Colbert, A. J. Hodge, M. S. Khan. Synthesis and characterisation of mono-acetylide and unsymmetrical bis-acetylide complexes of ruthenium and osmium: $\mathrm{X}$-ray structure determinations on [(dppe) $2 \mathrm{Ru}(\mathrm{Cl})(\mathrm{C} \equiv \mathrm{C}-\mathrm{C} 6 \mathrm{H} 4$-p- NO 2)],[(dppe) $2 \mathrm{Ru}(\mathrm{Cl})(\mathrm{C} \equiv \mathrm{C}-\mathrm{C} 6 \mathrm{H}$ $3-\mathrm{o}-\mathrm{CH} 3-\mathrm{p}-\mathrm{NO} 2)]$ and $[(\mathrm{dppm}) 2 \mathrm{Os}(\mathrm{C} \equiv \mathrm{C}-\mathrm{C} 6 \mathrm{H} 4-\mathrm{p}-\mathrm{CH} 3)(\mathrm{C} \equiv \mathrm{C}-\mathrm{C} 6$ H 4-p-NO 2)]. Journal of Organometallic Chemistry 578(1) (1999) 198209.

[24] N. Gauthier, N. Tchouar, F .d. r. Justaud, G. Argouarch, M. P. Cifuentes, L. Toupet, D. Touchard, J.-F. Halet, S. Rigaut, M. G. Humphrey. Bonding and electron delocalization in ruthenium (III) $\sigma$-arylacetylide radicals [trans- $\mathrm{Cl}\left(\eta^{2}-\right.$

$\left.\left.-\mathrm{C}_{6} \mathrm{H}_{4} \mathrm{X}\right)\right]+\left(\mathrm{X}=\mathrm{NO}_{2}, \mathrm{C}(\mathrm{O}) \mathrm{H}, \mathrm{C}(\mathrm{O}) \mathrm{Me}, \mathrm{F}, \mathrm{H}, \mathrm{OMe}, \mathrm{NMe}_{2}\right)$ : misleading aspects of the ESR anisotropy. Organometallics 28(7) (2009) 2253- 2266.

[25]D. Kharbani, D. K. Deb, I. L. Mawnai, S. D. Kurbah, B. Sarkar, E. Rymmai. Pyrazole cleavage of tris (3, 5-dimethylpyrazolyl) borate with Ruthenium (II) complexes: Synthesis, structural characterization and DFT studies. Journal of Molecular Structure 1133 (2017) 264-270.

[26]M. Y. Amusia, A. Msezane, V. Shaginyan. Density functional theory versus the hartree-fock method: Comparative assessment. Physica Scripta 68(6) (2003) C133.

[27]K. Manjunatha, R. Dileep, G. Umesh, M. Satyanarayan, B. R. Bhat. All optical nonlinear and switching characteristics of a novel ruthenium complex. Optical Materials 36(6) (2014) 1054-1059.

[28]S. K. Hurst, M. P. Cifuentes, J. P. Morrall, N. T. Lucas, I. R. Whittall, M. G. Humphrey, I. Asselberghs, A. Persoons, M. Samoc, B. Luther-Davies. Organometallic complexes for nonlinear optics. 22.1 quadratic and cubic hyperpolarizabilities of trans-bis (bidentate phosphine) ruthenium $\sigma$ arylvinylidene and $\sigma$-arylalkynyl complexes. Organometallics 20(22) (2001) 4664-4675.

[29] E. Kulasekera, S. Petrie, R. Stranger, M. G. Humphrey. DFT calculation of static first hyperpolarizabilities and linear optical properties of metal alkynyl complexes. Organometallics 33(10) (2014) 2434-2447.
[30]E. Kulasekera, S. Petrie, R. Stranger, M. P. Cifuentes, M. G. Humphrey, DFT/TD- DFT analysis of structural, electrochemical and optical data from mononuclear osmium and heterobinuclear osmium-ruthenium alkynyl complexes. Journal of Organometallic Chemistry 748 (2013)2128.

[31]C. E. Powell, M. P. Cifuentes, A. M. McDonagh, S. K. Hurst, N. T. Lucas, C. D. Delfs, R. Stranger, M. G. Humphrey, S. Houbrechts, I. Asselberghs. Organometallic complexes for nonlinear optics.: Part 27. Syntheses and optical properties of some iron, ruthenium and osmium alkynyl complexes. Inorganica Chimica Acta 352 (2003) 9-18.

[32]R. Misra. Tuning of second-order nonlinear optical response properties of arylsubstituted boron-dipyrromethene dyes: Unidirectional charge transfer coupled with structural tailoring. The Journal of Physical Chemistry C 121(10) (2017) 5731-5739.

[33]J. Prashanth, B. V. Reddy. Study on structure, vibrational analysis and molecular characteristics of some halogen substituted azidophenylethanones using FTIR spectra and DFT. Journal of Molecular Structure 1155 (2018) 582-597.

[34]N. Prabavathi, A. Nilufer, V. Krishnakumar. Spectroscopic (FT-IR, FTRaman, UV and NMR) investigation, conformational stability, NLO properties, HOMO-LUMO and NBO analysis of hydroxyquinoline derivatives by density functional theory calculations. Spectrochimica Acta Part A: Molecular and Biomolecular Spectroscopy 114 (2013) 449-474.

[35]M. I. Bruce, M. G. Humphrey, M. R. Snow, E. R. Tiekink. Cyclopentadienyl-ruthenium and-osmium chemistry: XXVII. X$\mathrm{CPh})(\mathrm{dppe})\left(\eta-\mathrm{C}_{5} \mathrm{H}_{5}\right)$ and of $\left[\mathrm{Ru}(\mathrm{L})\left(\mathrm{PPh}_{3}\right) 2\left(\eta-\mathrm{C}_{5} \mathrm{H}_{5}\right)\right] \mathrm{X}(\mathrm{L}=\mathrm{C}(\mathrm{OMe}) \mathrm{Et}$, $\mathrm{X}=-2)(1986) 213-225$.

[36] I. R. Whittall, M. G. Humphrey, D. C. Hockless, B. W. Skelton, A. H. White. Organometallic complexes for nonlinear optics. 2. Syntheses, electrochemical studies, structural characterization, and computationallyderived molecular quadratic hyperpolarizabilities of ruthenium. sigma.arylacetylides: X-ray Crystal Structures of $\mathrm{Ru}(\mathrm{C}$. tplbond. $\mathrm{CPh})\left(\mathrm{PMe}_{3}\right)_{2}$. eta. $\left.-\mathrm{C}_{5} \mathrm{H}_{5}\right)$ and $\mathrm{Ru}\left(\mathrm{C}\right.$. tplbond. $\left.\mathrm{CC}_{6} \mathrm{H}_{4} \mathrm{NO}_{2-4}\right)(\mathrm{L})_{2}\left(\right.$.eta. $\left.-\mathrm{C}_{5} \mathrm{H}_{5}\right)\left(\mathrm{L}=\mathrm{PPh}_{3}\right.$, $\mathrm{PMe}_{3}$ ). Organometallics 14(8) (1995) 3970-3979.

[37] M. A. Fox, J. E. Harris, S. Heider, V. Pérez-Gregorio, M.E. Zakrzewska, J. D. Farmer, D. S. Yufit, J. A. Howard, P. J. Low. A simple synthesis of trans-RuCl (CCR)(dppe) 2 complexes and representative molecular structures. Journal of Organometallic Chemistry 694(15) (2009) 23502358.

[38] M. P. Cifuentes, M. G. Humphrey. Alkynyl compounds and nonlinear optics. Journal of Organometallic Chemistry 689(24) (2004) 3968-3981. 